\title{
Minimally invasive spinopelvic "crab-shaped fixation" for unstable pelvic ring fractures: technical note and 16 case series
}

Akinori Okuda ${ }^{1,2}$, Naoki Maegawa ${ }^{1,2^{*}}$, Hiroaki Matsumori ${ }^{3}$, Tomohiko Kura $^{4}$, Yasushi Mizutani ${ }^{1,2}$, Hideki Shigematsu ${ }^{2}$, Eiichiro Iwata², Masato Tanaka², Keisuke Masuda², Yusuke Yamamoto², Yusuke Tada', Yohei Kogeichi', Keisuke Takano ${ }^{1}$, Hideki Asai ${ }^{1}$, Yasuyuki Kawai ${ }^{1}$, Yasuyuki Urisono ${ }^{1}$, Kenji Kawamura ${ }^{2}$, Hidetada Fukushima ${ }^{1}$ and Yasuhito Tanaka ${ }^{2}$

\begin{abstract}
Background: Unstable sacral fractures are high-energy injuries and comprise polytrauma. Internal fixation to enable withstanding vertical loads is required to get up early from the bed after an unstable sacral fracture. We developed a new minimally invasive surgical (MIS) procedure for unstable pelvic ring fractures and reported it in Japanese in 2010. We presented our minimally invasive surgical technique of crab-shaped fixation for the treatment of unstable pelvic ring fractures and report on its short-term outcomes.
\end{abstract}

Methods: Sixteen patients with unstable pelvic ring fractures (AO types $\mathrm{C} 1,2$, and 3) were treated using crabshaped fixation. All procedures were performed with the patient in the prone position through $5-\mathrm{cm}$ skin incisions created bilaterally at the level of the posterior superior iliac spine. Four iliac screws were inserted and connected with two rods under the fascia. Percutaneous pedicle screws were inserted at $L 5$ or $L 4$ and connected to the iliac rod using offset connectors. Fracture reduction was then performed.

Results: The average surgical time was $158 \mathrm{~min}$ (range, 117-230 min), with an intraoperative bleeding volume of $299 \mathrm{ml}$ (range, 80-480 ml). Thirty-three pedicle screws and 64 iliac screws were implanted with no instance of malpositioning or perforation. A surgical site infection developed in 2 of the 16 cases. Both were deep methicillinresistant Staphylococcus aureus infections, with the removal of the distal implants required in only one of these cases. Bony union was achieved in all patients, and all vertical displacements reduced by $7.0 \mathrm{~mm}$, on average (range, $5.4-9.0 \mathrm{~mm}$ ), to $<10 \mathrm{~cm}$. Correction was retained in all cases.

Conclusions: Crab-shaped fixation provides a feasible MIS approach for spinopelvic fixation, which allows good reduction of the vertical displacement of unstable pelvic ring fractures and bony union.

Keywords: Crab-shaped fixation, Pelvic ring fracture, Sacral fracture, Minimally invasive surgery, Spino-pelvic fixation, Vertical displacement

\footnotetext{
* Correspondence: nmaegawa@naramed-u.ac.jp

'Department of Emergency and Critical Care Medicine, Nara Medical

University, 840 Shijotyo, Kashihara City, Nara 654-8522, Japan

${ }^{2}$ Department of Orthopedic Surgery, Nara Medical University, Kashihara, Nara,

Japan

Full list of author information is available at the end of the article
}

(c) The Author(s). 2019 Open Access This article is distributed under the terms of the Creative Commons Attribution 4.0 International License (http://creativecommons.org/licenses/by/4.0/), which permits unrestricted use, distribution, and reproduction in any medium, provided you give appropriate credit to the original author(s) and the source, provide a link to the Creative Commons license, and indicate if changes were made. The Creative Commons Public Domain Dedication waiver (http://creativecommons.org/publicdomain/zero/1.0/) applies to the data made available in this article, unless otherwise stated. 


\section{Background}

Spinopelvic fixation (SPF), using spinal instrumentation, is a method of rigid fixation for unstable pelvic ring fractures [1-3]. The use of lumbar pedicle and iliac screws (with a bridging rod) reduces the vertical length of SPF required, while providing a rigid fixation across the sacrum, sacroiliac joints, and ilium that can withstand the shear load of vertical forces during weight-bearing activities. Schildhauer et al. reported that rigid SPF led to good bony union, without loss of segmental correction [3]. Moreover, the recent use of a minimally invasive surgical (MIS) approach for SPF lowered the risk for infection and injury to the skin and soft tissues, while providing a higher rate of union than that with conventional open fixation $[4,5]$. In 2014, we reported on our use, in Japan, of the "crab-shaped fixation" as a new MIS fixation technique for the treatment of unstable pelvic ring fractures, which reduces the vertical displacement of the fracture. We performed crab-shaped fixation on $\mathrm{AO}$ types $\mathrm{C} 1$ and $\mathrm{C} 3$ fractures with a large vertical dislocation or Denis zone III, $\mathrm{AO}-\mathrm{C} 2$, and $\mathrm{AO}-$ C3 fractures [6]. For crab-shaped fixation, percutaneous pedicle screws were inserted bilaterally into the pedicles of L5 or L4, and four iliac screws were inserted bilaterally into the iliac crests, with titanium-alloy rods used to connect the screws both in the right-left and craniocaudal directions. In this way, the crab-shaped fixation can withstand not only vertical loading but also

Table 1 Clinical data of cases included in our study group

\begin{tabular}{|c|c|c|c|c|c|c|c|c|c|c|c|c|}
\hline \multirow[t]{2}{*}{ No. } & \multirow[t]{2}{*}{ Age } & \multirow[t]{2}{*}{ Sex } & \multirow[t]{2}{*}{ ISS } & \multirow{2}{*}{$\begin{array}{l}\text { Cause of } \\
\text { trauma }\end{array}$} & \multirow[t]{2}{*}{ AO classification } & \multirow{2}{*}{$\begin{array}{l}\text { Operation } \\
\text { time (min) }\end{array}$} & \multirow{2}{*}{ Blood loss (g) } & \multicolumn{2}{|c|}{ Vertical dislocation (mm) } & \multirow{2}{*}{$\begin{array}{l}\text { Reduction } \\
\text { rate (\%) }\end{array}$} & \multirow[t]{2}{*}{ Complication } & \multirow{2}{*}{$\begin{array}{l}\text { Bony } \\
\text { union }\end{array}$} \\
\hline & & & & & & & & Pre op & Post op & & & \\
\hline 1 & 21 & $\mathrm{~F}$ & 17 & $\begin{array}{l}\text { Attempted } \\
\text { suicide } \\
\text { jump }\end{array}$ & $\mathrm{C} 2$ & 170 & 310 & 10.4 & 5 & 52 & & Union \\
\hline 2 & 29 & $\mathrm{~F}$ & 27 & $\begin{array}{l}\text { Struck by a } \\
\text { vehicle }\end{array}$ & C3 & 180 & 400 & 18.4 & 8.9 & 52 & & Union \\
\hline 3 & 19 & $\mathrm{~F}$ & 14 & $\begin{array}{l}\text { Traffic } \\
\text { accident }\end{array}$ & C3 & 168 & 480 & 4.8 & 4.8 & & & Union \\
\hline 4 & 69 & $\mathrm{~F}$ & 22 & $\begin{array}{l}\text { Struck by a } \\
\text { vehicle }\end{array}$ & C3 & 131 & 200 & 5 & 5 & & & Union \\
\hline 5 & 75 & M & 21 & $\begin{array}{l}\text { Struck by a } \\
\text { vehicle }\end{array}$ & $\mathrm{C} 2$ & 172 & 200 & 2.4 & 2.4 & & & Union \\
\hline 6 & 36 & $\mathrm{~F}$ & 29 & $\begin{array}{l}\text { Attempted } \\
\text { suicide } \\
\text { jump }\end{array}$ & $\mathrm{C} 2$ & 157 & 320 & 1.5 & 1.5 & & & Union \\
\hline 7 & 59 & $\mathrm{~F}$ & 29 & $\begin{array}{l}\text { Traffic } \\
\text { accident }\end{array}$ & $C 2$ & 120 & 150 & 2 & 2 & & SSI (MRSA) & Union \\
\hline 8 & 64 & M & 26 & $\begin{array}{l}\text { Struck by a } \\
\text { vehicle }\end{array}$ & C3 & 171 & 300 & 1.5 & 1.5 & & & Union \\
\hline 9 & 50 & M & 29 & $\begin{array}{l}\text { Traffic } \\
\text { accident }\end{array}$ & $C 2$ & 117 & 250 & 12 & 6.5 & 46 & & Union \\
\hline 10 & 40 & $\mathrm{~F}$ & 41 & $\begin{array}{l}\text { Run over } \\
\text { by a } \\
\text { vehicle }\end{array}$ & C3 & 184 & 450 & 2.2 & 2.2 & & $\begin{array}{l}\text { Gluteal muscle } \\
\text { necrosis, SSI (MRSA) }\end{array}$ & Union \\
\hline 11 & 46 & M & 22 & $\begin{array}{l}\text { Attempted } \\
\text { suicide } \\
\text { jump }\end{array}$ & $\mathrm{C} 2$ & 155 & 480 & 18 & 9 & 50 & & Union \\
\hline 12 & 82 & M & 38 & $\begin{array}{l}\text { Traffic } \\
\text { accident }\end{array}$ & $C 2$ & 120 & 80 & 10.5 & 5 & 52 & & Union \\
\hline 13 & 50 & $\mathrm{~F}$ & 38 & $\begin{array}{l}\text { Traffic } \\
\text { accident }\end{array}$ & C1 & 132 & 120 & 18.3 & 12 & 34 & & Union \\
\hline 14 & 59 & M & 24 & $\begin{array}{l}\text { Struck by a } \\
\text { vehicle }\end{array}$ & C3 & 230 & 350 & 15 & 7.5 & 50 & & Union \\
\hline 15 & 51 & M & 26 & $\begin{array}{l}\text { Traffic } \\
\text { accident }\end{array}$ & $C 2$ & 150 & 267 & 15 & $7.5(5.0)$ & 50 & $\begin{array}{l}\text { Lt L5 nerve root pain } \\
\text { remained.Re-operation } \\
\text { performed. }\end{array}$ & Union \\
\hline 16 & 53 & M & 22 & $\begin{array}{l}\text { Struck by a } \\
\text { vehicle }\end{array}$ & $\mathrm{C} 2$ & 175 & 430 & 1 & 1 & & & Union \\
\hline
\end{tabular}


horizontal and rotational loading. The purpose of this study was to describe the surgical procedure for MIS crab-shaped fixation and to report on clinical outcomes.

\section{Methods}

Patients consented to have their case data collected and used for publication.

The study group included 16 patients who were treated for an unstable pelvic ring fracture, between 2010 and 2016. All fractures were AO type C, including 1 type $\mathrm{C} 1$ fracture with $>10 \mathrm{~mm}$ of vertical displacement, 9 type $\mathrm{C} 2$ fractures, and 6 type C3 fractures (Table 1). The average age at the time of trauma was 50 years (range, 19-82 years). There were 8 men and 8 women, with an average Injury Severity Score of 27 (range, 14 to 41 ). The causes of trauma included the following: being struck by a vehicle (7 patients), including 1 case of being run over by a vehicle; motor vehicle accidents ( 6 patients); and a suicide attempt by jumping from a height (3 patients). Surgery was performed once patients were sufficiently stable.

All crab-shaped spinopelvic fixations were performed using an MIS approach. We made a 5-cm incision along the medial border of the posterior superior iliac spine (PSIS) (Fig. 1a). We then proceeded with resection of the iliac bone $(3 \mathrm{~cm}$ in length, to a depth of $2 \mathrm{~cm}$ ), preserving the superior surface of the PSIS (Fig. 1b). Bone resection was performed to ensure that there would be no protrusion of the heads of the screws, to prevent postoperative irritation and skin necrosis. We inserted two iliac screws on each side, using a free-hand technique with an equal distance between the screws. In each case, we used large iliac screws ( $>7 \mathrm{~mm}$ in diameter and with a length $\geq 65 \mathrm{~mm}$, as possible
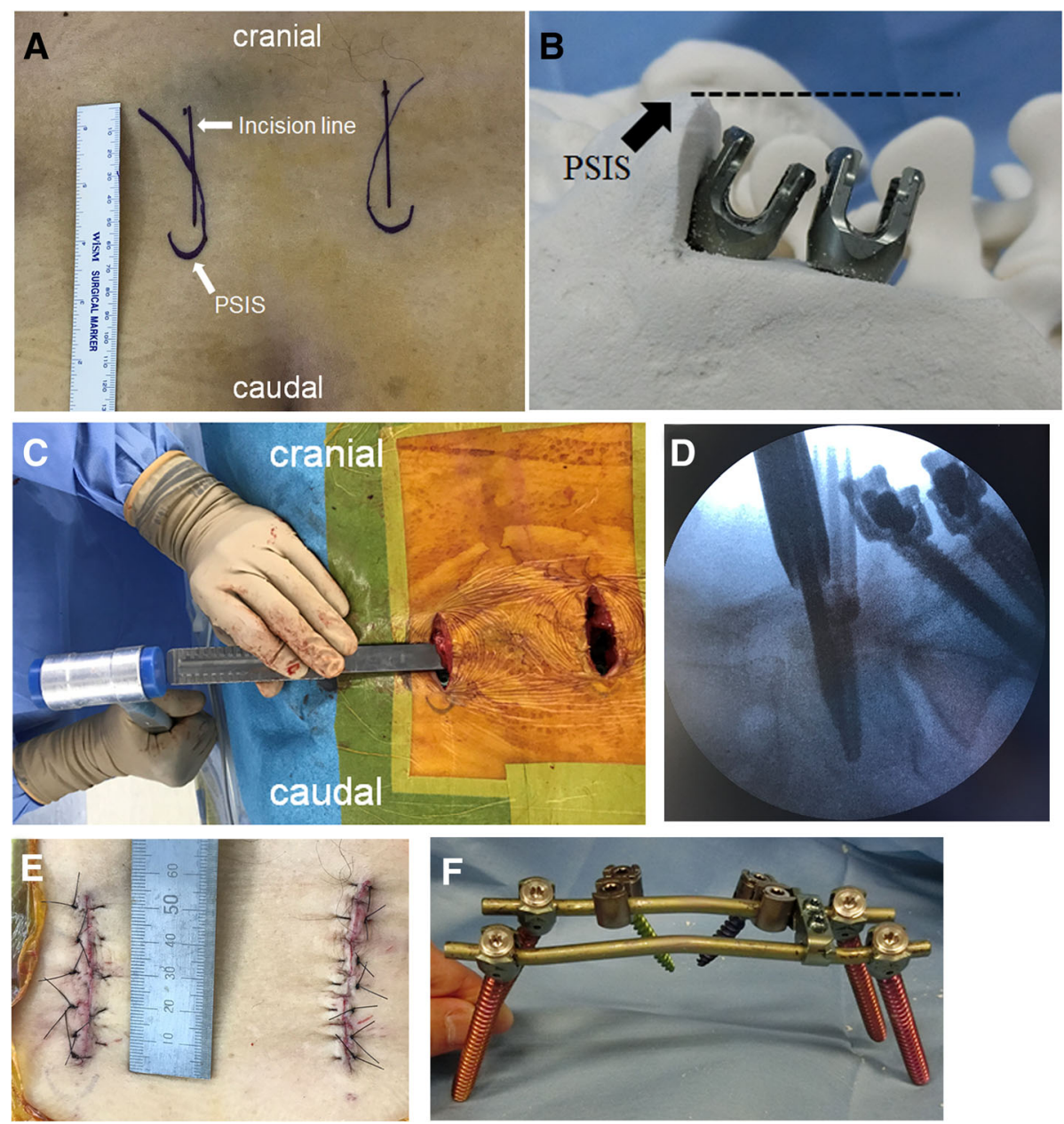

Fig. 1 Surgical procedure using the crab-shaped fixation. a A 5-cm incision line is created along the posterior superior iliac spine (PSIS). b The PSIS is resected (2-cm depth and 3-cm length), leaving the top of the PSIS intact. The iliac screws are inserted from the resection site of the ilium, using a free-hand technique, with the screw heads set lower than the top of PSIS to prevent skin breakdown (dotted line). c The spinous process of S1 is cut under the fascia to allow a smooth insertion of the rod. $\mathbf{d}$ Percutaneous pedicle screws at L5 or L4 are inserted, via the same incision, under fluoroscopic guidance. e Postoperative wound closure. $\mathbf{f}$ The crab-shaped fixation is shown 
in each case). The iliac screws were set lower than the top of the PSIS, as shown by the dotted line in Fig. 1b. We also removed the spinous process of S1 using a chisel, below the fascia, in cases where the spine interfered with insertion of the rod connecting the left and right screws (Fig. 1c). We connected the two upper and lower rods using one or two transverse connectors. Percutaneous pedicle screws (PPSs) were then set into L5 (or L4), through the same incisions along the PSIS, under image guidance, using a C-arm fluoroscope (WHA-200 OPESCOPE ACTIVO, Shimadzu Medical; Fig. 1d). Offset connectors were installed in the connecting rods implanted in the iliac bone and were then connected to the PPSs. We then proceeded with vertical reduction of the fracture through distraction between the ipsilateral PPS and offset connector rod. It is difficult to confirm whether the reduction is appropriate in MIS as it is complicated to perform direct reduction. Therefore, we performed the reduction by being aware of the following three points: (1) confirming the reduction by palpating the step off and gap of the fracture site using a finger during reduction, (2) measuring the reduction distance in advance with preoperative $\mathrm{CT}$ and reducing by the same distance, and (3) confirming the reduction under fluoroscopy with the outlet view. When we reduce the transversal displacement, we perform compression between the right and left the iliac screws or offset connector and ipsilateral iliac screw as long as the reduction distance matches with that measured in advance with preoperative $\mathrm{CT}$, and we confirm the reduction on AP view under fluoroscopy. With accumulated experience, we changed the pedicle screws that we use for the fixation to the PPS system for MIS. We first used the open pedicle screw system (USS2 poly-axial system, SYNTHES), subsequently changing to the percutaneous pedicle screw system (SpiRIT Pangea system, SYNTHES). Currently, we use the new percutaneous pedicle screw system (Matrix-X-tab system, Depuy-SYNTHES, or CREO-MIS, Globus).

The following variables were used to evaluate clinical outcomes: operative time, intraoperative bleeding volume, screw perforation and malpositioning, surgical site
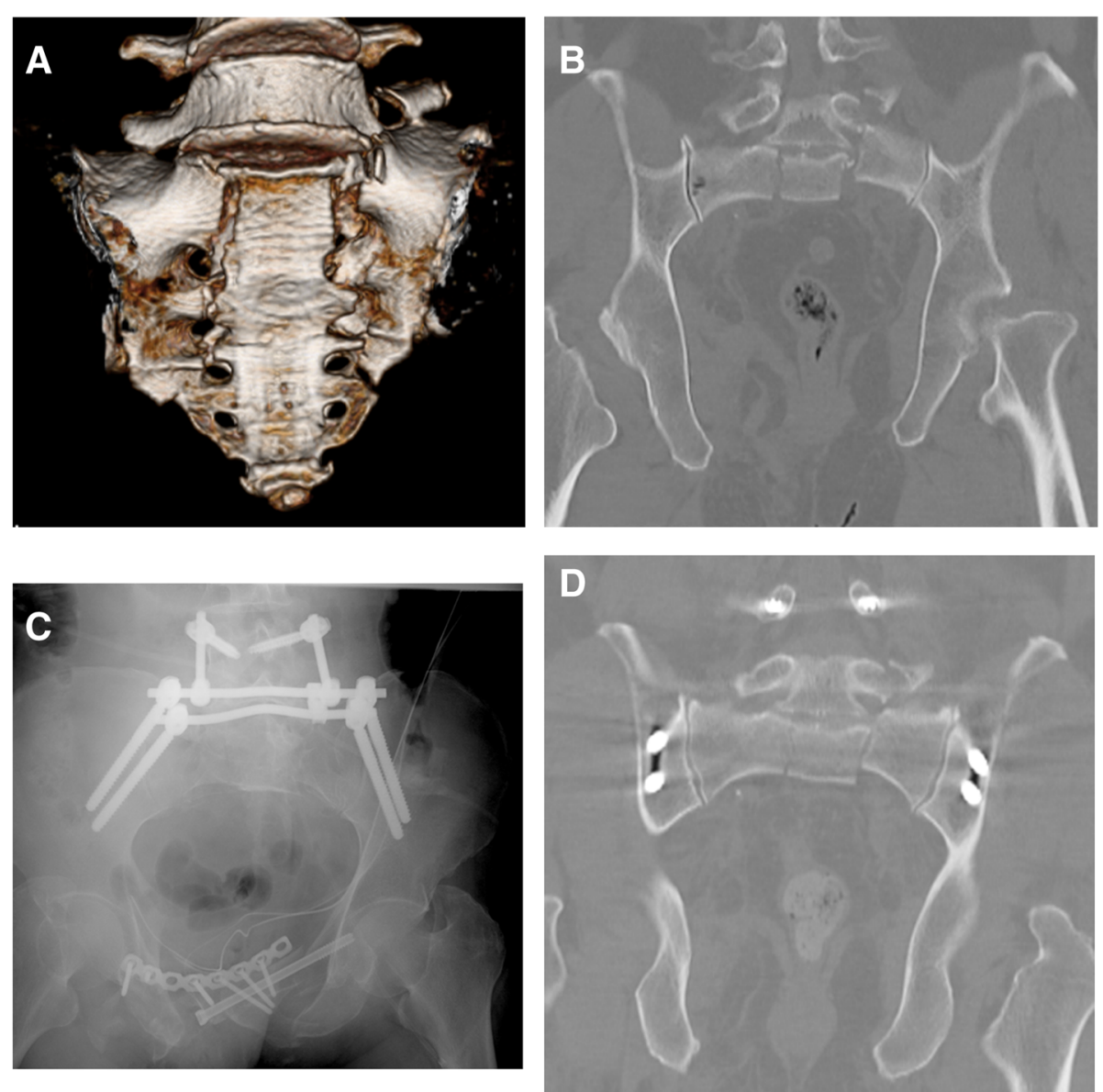

Fig. 2 Case 15: a 45-year-old male who sustained an unstable AO type C2 pelvic ring fracture in a traffic accident, including a bilateral fracture of the Denis zone II of the sacrum and a 15-mm vertical dislocation (cranial direction). a Preoperative three-dimensional computed tomography (CT), showing the H-shaped sacral fracture. b The 15-mm vertical dislocation (cranial direction) is observable on the preoperative coronal plane $C T$. c Postoperative radiographs, showing the crab-shaped fixation. $\mathbf{d}$ Postoperative $C T$ showing a residual $7.5-\mathrm{mm}$ vertical dislocation (cranial direction) 
infection (SSI), rate of bony union, and rate of achieving vertical reduction of the fracture.

\section{Results}

The average surgical time was 158 min (range, 117 to $230 \mathrm{~min}$ ), with an intraoperative bleeding volume of 299 $\mathrm{ml}$ (range, 80 to $480 \mathrm{ml}$; Table 1). The incidence of malpositioning of the lumbar pedicle screws and perforation of the iliac screws was evaluated using computed tomography $(\mathrm{CT})$ based on the classifications given by Rao et al. [7] and Koshimune et al. [5], respectively. Among the 16 cases, we implanted 33 pedicle screws and 64 iliac screws, with no incidence of screw malpositioning or perforation.

With regard to complications, SSI developed in 2 of the 16 cases. In both cases, the infections were deep methicillin-resistant Staphylococcus aureus (MRSA) infections. Treatment included debridement and negative pressure wound therapy (NPWT), with one patient requiring removal of the distal implants (left and right iliac screws), with the proximal implants remaining in situ (both iliac screws and L5 pedicle screws). In the other case, gluteal necrosis developed after transcatheter arterial embolization (TAE), which resulted in deep infection. The patient was treated with debridement and NPWT without the removal of the implants. After bony union was achieved at 3 months, all implants were removed and the infection was cured.

Bony union was achieved in all 16 cases. Among the 16 cases, 8 presented with a vertical displacement $\geq 10$ $\mathrm{mm}$. The average reduction length was $7.0 \mathrm{~mm}$ (range, 5.4 to $9.0 \mathrm{~mm}$ ), with an average reduction of the vertical displacement of $48 \%$ (range, $34 \%$ to $52 \%$; Table 1 ). Among the 8 cases with vertical displacement, a residual displacement of $\geq 10 \mathrm{~mm}$ was identified in only one case, with no associated neurological symptoms from the lumbosacral plexus. In one of these cases (case 15), we reduced the vertical displacement from $15 \mathrm{~mm}$ to 7.5 $\mathrm{mm}$, but the patient complained of pain caused by L5 nerve root entrapment (Fig. 2). Radiculography of the L5 nerve root, using a contrast agent, confirmed impingement of the nerve root, shown by the black arrow in Fig. 3, with stimulation of the nerve root reproducing the patient's pain. As the residual vertical displacement of the fracture was compressing the nerve root, we proceeded with a repeat reduction of the fracture, successfully decreasing the residual displacement to $5 \mathrm{~mm}$, with resolution of the neurological symptoms (Fig. 4). Of the eight patients who underwent fracture reduction, postoperative correction was maintained in all cases.

\section{Discussion}

SPF and sacroiliac rod fixation (SIRF) have previously been described as MIS techniques with spinal

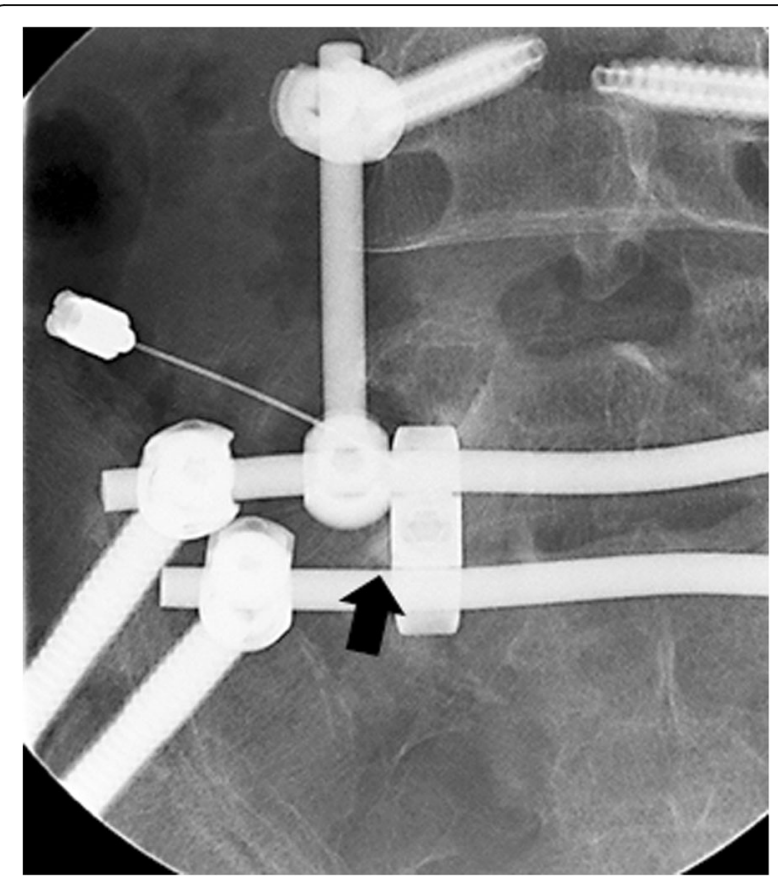

Fig. 3 Radiculography of the left $L 5$ nerve root, performed with a contrast agent, with root impingement in the lumbosacral tunnel (black arrow) observable on the posterior-anterior view

instrumentation capable of reducing the vertical displacement of unstable pelvic ring fractures $[4,5]$. Koshimune et al. performed SPF using the percutaneous spinal pedicle screw system [5], whereas Futamura et al. performed SIRF by linking each left and right iliac screw with a rod and connecting these to percutaneous S1 pedicle screws using offset connectors [4]. To perform the vertical reduction of the fracture, a Schanz screw was inserted into the L5 pedicle, and the vertical displacement of the fracture was reduced by distraction. However, the L5 pedicle screw was not used for fixation. Rather, the Schanz screw was removed after reduction while preserving the mobility of the L5/S1 facet joint [4]. The reported relevant outcomes for SPF and SIRF, respectively, were as follows: operative time, $208 \mathrm{~min}$ and $179 \mathrm{~min}$; intraoperative blood loss, $290 \mathrm{~g}$ and $533 \mathrm{~g}$; rate of SSI, $0 \%$ and 6.7\%; and screw malpositioning, 0 and 1 screw. Bony union was achieved in all cases for both procedures. In contrast to conventional (open) sacral fixation, percutaneous SPF decreases operative time and intraoperative bleeding volume. It also has a low rate of postoperative infections while providing the rigid fixation needed for a high rate of bony union [5]. Bellabarba et al. reported that $42 \%$ of patients who underwent lumbosacral fixation using an open method required secondary surgery because of complications, which included deep infection (16\%), implant irritation (11\%), hematoma and seroma formation (10\%), and skin ulceration (5\%) [1]. Sagi et al. 

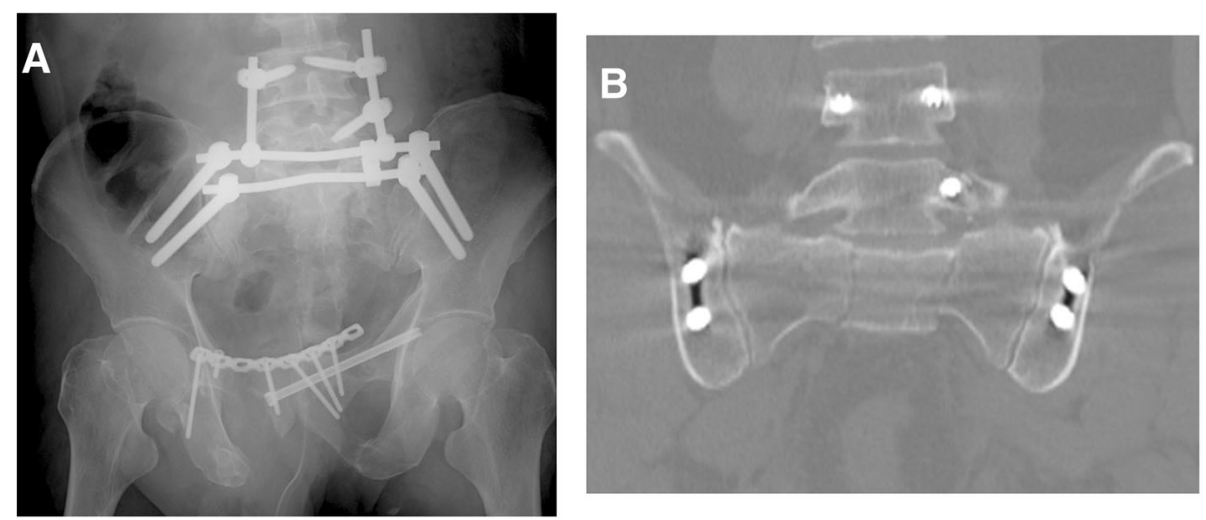

Fig. 4 Radiograph and computed tomography (CT) images after surgery. a Anteroposterior radiograph, showing the left L5 pedicle screw, after secondary surgery, which is used to apply distraction to the fracture site (in combination with traction of the left lower limb). $\mathbf{b}$ Coronal CT after secondary surgery, showing the residual 5-7.5-mm residual vertical dislocation (cranial direction), but with resolution of the left L5 nerve root pain

also reported that $16 \%$ of patients who undergo open lumbosacral fixation require implant removal due to an SSI [2].

In our case series, the use of the crab-shaped fixation further decreased operative time, in contrast to that for SPF and SIRF, with an intraoperative blood loss volume that was similar to that previously reported for SPF. Our rate of SSI (2 cases; $12.5 \%$ ) was comparable to the rate for both SPF and SIRF. Regarding the nature of the SSI in our two cases, one was secondary to a gluteal necrosis that developed after TAE of the superior gluteal artery at the surgical site. The other SSI case was an MRSA carrier.

The crab-shaped fixation provided sufficient rigidity to achieve bony union in all cases, with no loss of correction, even in the two cases of SSI without complete removal of implants by using NPWT. Therefore, the crab-shaped fixation provides a feasible MIS alternative for spinopelvic fixation.

Lumbosacral plexus symptoms can develop when a strong traction force is applied to the sacrum for reduction of the vertical displacement of the fracture. The L5 nerve root may also be compressed in the lumbosacral tunnel with AO type $\mathrm{C}$, which includes a vertical displacement of the Denis zone I or II of the sacrum of $\geq$ $10 \mathrm{~mm}[6,8]$. Therefore, fracture reduction should aim to decrease the vertical displacement to $<10 \mathrm{~mm}$. Among our 16 cases, 1 patient developed L5 nerve root pain secondary to compression of the root in the lumbosacral tunnel, despite a reduction in the vertical displacement of the AO type $\mathrm{C} 2$ (sacral $\mathrm{H}$-shaped fracture) from $15 \mathrm{~mm}$ preoperatively to $7.5 \mathrm{~mm}$ postoperatively (Table 1 , case 15). We performed secondary surgery to further reduce the vertical displacement from $7.5 \mathrm{~mm}$ to $5.0 \mathrm{~mm}$, which was achieved by using lower limb traction in combination with distraction using instrumentation.
Based on this experience, it might be necessary to reduce the sacral vertical dislocation to within $5 \mathrm{~mm}$.

The interpretation of our findings should be considered within the limitations of our study, which included a small number of cases; the absence of biomechanical data and the need for implant removal after bony union as it provided fixation across the L5/S1 facet joint. We may further evaluate the biomechanical data of crab-shaped fixation focusing on the appropriate or minimum size and length of the iliac screw to endure shear load force.

\section{Conclusion}

Crab-shaped fixation provides a feasible MIS approach for spinopelvic fixation that provides sufficient rigidity to achieve bony union in the treatment of unstable pelvic ring fractures. This technique provides an easy way to achieve good reduction of the vertical displacement of the fracture.

\section{Abbreviations}

CT: Computed tomography; MIS: Minimally invasive surgery; MRSA: Methicillin-resistant Staphylococcus aureus; NPWT: Negative pressure wound therapy; PPS: Percutaneous pedicle screw; PSIS: Posterior superior iliac spine; SIRF: Sacroiliac rod fixation; SPF: Spinopelvic fixation; SSI: Surgical site infection; TAE: Transcatheter arterial embolization

\section{Acknowledgements}

Not applicable.

\section{Funding}

No funding was provided specifically for this project.

\section{Availability of data and materials}

Please contact author for data requests.

\section{Authors' contributions}

$\mathrm{NM}, \mathrm{HM}, \mathrm{TK}, \mathrm{HS}$, and KK conceived and designed the study. YM, YT, YK, KT, $H A, Y K$, and $Y U$ collected the data. AO wrote the manuscript. El, MT, KM, YY, $H F$, and $Y T$ read, corrected, and approved the final manuscript. All authors read and approved the final manuscript. 


\section{Ethics approval and consent to participate}

This study was approved by the ethics committee of Nara Medical University. The approval number is 1951. As for this research, an optout of the informed consent, the information disclosure, and a negative opportunity are guaranteed in the Ethical approval.

\section{Consent for publication}

All the patients in this study have given their informed consent for the article to be published.

\section{Competing interests}

The authors declare that they have no competing interests.

\section{Publisher's Note}

Springer Nature remains neutral with regard to jurisdictional claims in published maps and institutional affiliations.

\section{Author details}

'Department of Emergency and Critical Care Medicine, Nara Medical University, 840 Shijotyo, Kashihara City, Nara 654-8522, Japan. ${ }^{2}$ Department of Orthopedic Surgery, Nara Medical University, Kashihara, Nara, Japan. ${ }^{3}$ Department of Orthopedic Surgery, Kashiba Asahigaoka Hospital, Kashiba, Nara, Japan. ${ }^{4}$ Department of Orthopedic Surgery, Kura Hospital, Ikoma, Nara, Japan.

Received: 6 September 2018 Accepted: 5 February 2019

Published online: 15 February 2019

\section{References}

1. Bellabarba C, Schildhauer TA, Vaccaro AR, Chapman JR. Complications associated with surgical stabilization of high-grade sacral fracture dislocations with spino-pelvic instability. Spine. 2006;31:580-8.

2. Sagi HC, Militano U, Caron T, Lindvall E. A comprehensive analysis with minimum 1-year follow-up of vertically unstable transforaminal sacral fractures treated with triangular osteosynthesis. J Orthop Trauma. 2009;23: $313-21$

3. Schildhauer TA, Bellabarba C, Nork SE, Barei DP, Routt ML Jr, Chapman JR. Decompression and lumbopelvic fixation for sacral fracture-dislocations with spino-pelvic dissociation. J Orthop Trauma. 2006;20:447-57.

4. Futamura K, Baba T, Mogami A, Kanda A, Obayashi O, Iwase H, et al. "within ring"-based sacroiliac rod fixation may overcome the weakness of spinopelvic fixation for unstable pelvic ring injuries: technical notes and clinical outcomes. Int Orthop. 2018;42:1405-11.

5. Koshimune K, Ito Y, Sugimoto Y, Kikuchi T, Morita T, Mizuno S, et al. Minimally invasive spinopelvic fixation for unstable bilateral sacral fractures. Clin Spine Surg. 2016;29:124-7.

6. Denis F, Davis S, Comfort T. Sacral fractures: an important problem. Retrospective analysis of 236 cases. Clin Orthop Relat Res. 1988;227:67-81.

7. Rao G, Brodke DS, Rondina M, Bacchus K, Dailey AT. Inter- and intraobserver reliability of computed tomography in assessment of thoracic pedicle screw placement. Spine. 2003;28:2527-30.

8. Sugimoto $Y$, Ito $Y$, Tomioka M, Tanaka M, Hasegawa Y, Nakago $K$, et al. Risk factors for lumbosacral plexus palsy related to pelvic fracture. Spine. 2010; 35:963-6.

Ready to submit your research? Choose BMC and benefit from:

- fast, convenient online submission

- thorough peer review by experienced researchers in your field

- rapid publication on acceptance

- support for research data, including large and complex data types

- gold Open Access which fosters wider collaboration and increased citations

- maximum visibility for your research: over $100 \mathrm{M}$ website views per year

At $\mathrm{BMC}$, research is always in progress.

Learn more biomedcentral.com/submissions 